\title{
Percepção de futuros docentes portugueses acerca da sub-representação feminina nas áreas e carreiras científico-tecnológicas
}

\author{
Isabel M. B. Fernandes ${ }^{1}$ \\ Sofia Cardim ${ }^{1}$
}

\section{Resumo}

0 desinteresse das alunas pelas áreas da ciência, tecnologia, engenharia e matemática (CTEM) condiciona as suas escolhas por carreiras científicas e tecnológicas, que são, muitas vezes, influenciadas pela forma tradicional de ensinar ciências e pela imagem androcêntrica que os/as docentes têm acerca da ciência, geralmente associada a estereótipos de gênero atribuídos às profissões. Assim, para perceber qual a percepção de futuros docentes portugueses acerca da acerca da sub-representação feminina nas áreas e carreiras CTEM, foram definidos dois objetivos de investigação: 1) Perceber se os/as futuros/as docentes consideram haver profissões típicas de determinado gênero ou profissões em que prevalece a invisibilidade feminina; 2) Perceber se os/as futuros/as docentes acreditam haver diferenças de aptidões entre homens e mulheres, bem como se consideram que a prática pedagógica pode influenciar o interesse e as escolhas profissionais dos/as alunos/as por carreiras científicas e tecnológicas. Adotou-se uma investigação essencialmente qualitativa, tendo sido aplicado um questionário a 28 estudantes do curso de mestrado em Educação PréEscolar e Ensino do $1^{\circ}$ Ciclo do Ensino Básico. Foram definidas categorias de análise que permitiram analisar as respostas dadas pelos participantes. Os resultados mostram que a maioria dos/as participantes demonstra ter falta de formação nesta área; outros manifestam concepções/crenças androcêntricas acerca dessas questões, o que compromete a sua prática pedagógica, enquanto intervenientes na socialização e formação de futuros/as cidadãos e cidadãs. Portanto, é necessário que a sua formação abarque a compreensão destes temas, permitindo-lhes desenvolver um sentido crítico sobre as suas próprias estereotipias e poderem também eles desmistificar e desconstruir estereótipos de gênero.

\section{Palavras-chave}

Gênero - Ciência - Formação de professores - Escolhas profıssionais - Invisibilidade feminina.

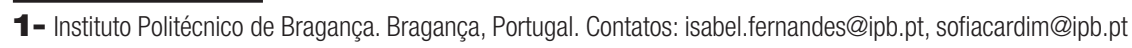

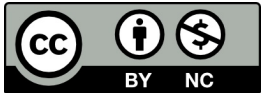




\section{Perception of future Portuguese teachers about female underrepresentation in scientific- -technological areas and careers}

\section{Abstract}

Female students' lack of interest in science, technology, engineering and mathematics (STEM) conditions their choices for scientific and technological careers, which are often influenced by the traditional way of teaching science, and by the androcentric image that teachers have about science, usually associated with gender stereotypes attributed to professions. Thus, to understand the perception of future Portuguese teachers about the underrepresentation of women in the STEM areas and careers, two research objectives were defined: 1) To perceive if future teachers consider that there are typical occupations of a certain gender or professions in which female invisibility prevails; 2) To understand if future teachers perceive that there are differences of aptitudes between men and women, as well as whether they consider that the pedagogical practice can influence the interest and the professional choices of the students towards scientific and technological careers. An essentially qualitative investigation was adopted, and a questionnaire was applied to 28 students of the master's degree course in Pre-School Education and Teaching of the First Cycle of Basic Education. Categories of analysis were defined that allowed to analyse the answers given by the participants. The results show that most participants demonstrate a lack of training in this subject; others express androcentric conceptions / beliefs about these issues, which compromise their pedagogical practice, since they interfere with the socialization and formation of future citizens. Therefore, it is necessary that their training include an understanding of gender issues, allowing them to develop a critical sense of their own stereotypes and to demystify and deconstruct gender stereotypes.

\section{Keywords}

Gender - Science - Teachers training - Professional choices - Female invisibility.

\section{Introdução}

Ao longo da História, a ciência e tecnologia têm sido caracterizadas como um mundo dominado essencialmente pelos homens, onde a representação feminina tem permanecido escondida e o papel das mulheres e as suas contribuições científicas se têm mantido invisíveis ou geralmente ignoradas. Vários estudos relacionados com as questões de gênero e a ciência têm mostrado uma quase ausência de registros da produção científica feminina e da sua participação na história da ciência, que significativamente contribuiu para a dinâmica e construção do conhecimento científico ao longo da História (BATISTA et al., 2013; CAMACHO-GONZÁLEZ, 2013). 
A questão da (in)visibilidade feminina não se faz notar apenas na História da Ciência, mas também nos ambientes de ensino. Embora as mulheres tenham feito progressos importantes na sua participação no ensino superior, essencialmente nas últimas quatro décadas, e figurem em maior número do que os homens, ainda estão sub-representadas nas áreas da ciência, tecnologia, engenharia e matemática - CTEM (EURYDICE, 2011; EUROPEAN COMMISSION, 2015; BERGANO, 2015). Esta situação que se faz sentir no ensino superior sugere, tal como defendem Fiúza, Pinto e Costa (2016), que a formação universitária também ainda não foi capaz de inverter os estereótipos de gênero que ainda existem na sociedade atual e que preconizam e determinam o tipo de profissão considerado adequado para homens e mulheres.

Em Portugal, tal como acontece em quase todos os países europeus, a percentagem de homens e de mulheres varia consideravelmente entre as diferentes áreas de estudo no ensino superior. No que respeita à graduação no ensino superior, no ano de 2014, a taxa de feminização era de 53,5\%, o que evidencia uma representação superior das mulheres face aos homens. Todavia, no que concerne à representação feminina por curso, verificase que a taxa de feminização atinge valores elevados nos domínios da educação (80,7\%), da saúde (76,6\%) e das ciências sociais ou artes (58,5\%), enquanto, por exemplo, nos domínios da engenharia (26,7\%) e ciências, matemáticas e informática (47,5\%) os valores são mais baixos (COMISSÃO..., 2014).

Assim, ainda prevalece a ideia de que as áreas das ciências e a das engenharias são consideradas masculinas e adequadas a homens, enquanto que as áreas relacionadas com a educação ou saúde são definidas como femininas e, portanto, mais adequadas a mulheres. Em particular, na área da educação, a profissão docente é exercida principalmente por mulheres, especialmente nos primeiros níveis de ensino, enquanto no ensino superior a concentração de profissionais é majoritariamente masculina (EURYDICE, 2011; EUROPEAN COMMISSION, 2015; BERGANO, 2015). No entanto, apesar desses valores, em nível europeu, Portugal é um dos países em que as mulheres optam em maior proporção pelas áreas das matemáticas, ciências e engenharia (COMISSÃO..., 2014).

As escolhas de muitas alunas pelas carreiras de ciência, tecnologia, engenharia e matemática (CTEM) são influenciadas por estereótipos socioculturais que persistem em atribuir determinados postos de trabalho apenas a homens (BERGANO, 2015; CASTILLO, GRAZZI; TACSIR, 2014). No contexto institucional, as experiências escolares das alunas são, muitas vezes, influenciadas pela prática pedagógica dos/as professores/as, também ela associada a estereótipos de gênero, que condicionam as suas escolhas profissionais (MORALES; AVILLA; ESPINOSA, 2016; SAAVEDRA et al., 2011, 2014; SAAVEDRA; TAVEIRA; SILVA, 2010; SCHIEBINGER, 2010). Neste contexto, as normas culturais e os estereótipos podem afetar o acesso das mulheres a carreiras nas áreas CTEM.

A sub-representação do sexo feminino nestes domínios (CTEM), e a consequente segregação da mulher no mercado de trabalho nestas áreas, está relacionada com a persistente ideia errônea da sociedade em geral, e da instituição escolar em particular, em associar e categorizar esses cursos como tipicamente masculinos (BERGANO, 2015). Desde muito novas, a visão pessoal que as crianças adquirem acerca das profissões e do mundo do trabalho vai construindo-se através de informações que vão recolhendo nos seus contextos 
mais próximos (FLOURI et al., 2015) como a família e a escola. Através do processo de socialização do qual fazem parte a família, a escola e a sociedade em geral, as crianças começam a associar determinadas profissões como sendo mais apropriadas a determinado sexo e, por conseguinte, diferenciam alguns domínios e profissões tradicionalmente femininas e outras tradicionalmente masculinas (MARTINS, 2011; SAAVEDRA et al., 2011, 2014; SAAVEDRA; TAVEIRA; SILVA, 2010).

0 fator gênero influencia as preferências profissionais das crianças nos primeiros anos de escolaridade: as meninas têm preferência por atividades e profissões socialmente atribuídas às mulheres como, por exemplo, cabeleireira e professora, enquanto os meninos preferem profissões caraterísticas do gênero masculino, como futebolista, polícial ou engenheiro. As preferências profissionais associadas ao fator gênero resultam de estereótipos que tendem a persistir no âmbito educacional (ARCHER; DEWITT; WONG, 2014; DEWITT et al., 2013; TRACEY; CAULUM, 2015; VERVECKEN; HANNOVER; WOLTER, 2013) do qual fazem parte pais e professores que, frequentemente, transmitem expectativas e, por vezes, impõem exigências diferenciadas para rapazes e raparigas (LARANJEIRA, 2015; LARANJEIRA; TEIXEIRA, 2016).

Nesta linha de pensamento, de acordo com Paixão e Silva (2015) e Fouad et al. (2017), as razões que levam muitas raparigas a evitarem escolher percursos educativos e profissionais nas áreas CTEM relacionam-se com as percepções de competência e expectativas de resultado desses percursos, nos quais a autoconfiança incentivada, ou não, pelos pais e professores desempenha um papel determinante nessas escolhas.

Os estereótipos de gênero são apontados como a principal causa que coíbe as alunas de partilharem as mesmas experiências que os alunos, impedindo-as de atingir o seu pleno potencial nas disciplinas de CTEM, limitando-lhes o acesso a carreiras acadêmicas. Deste modo, para incentivar o interesse de todos os alunos e, especialmente, das alunas por áreas CTEM, têm-se implementado inovações no ensino das ciências que visam a despertar nos alunos, e particularmente nas alunas, interesses, capacidades e motivações para um melhor desenvolvimento pessoal e social, mas que também têm a intenção de melhorar a formação de educadores e professores. Porém, essas metas educativas nem sempre coincidem com a educação científica que se faz em sala de aula (LESLIE et al., 2015).

As concepções sobre gênero e ciência dos/as professores/as são geralmente caraterizadas como androcêntricas ao envolverem o uso de linguagem sexista e o uso excessivo do masculino. Esta situação, por vezes, é reforçada pelos manuais escolares utilizados em sala de aula que, raramente, referem o papel da mulher e a sua participação na ciência e, quando o fazem, ainda é representado de uma maneira estereotipada evidenciando uma imagem androcêntrica e tradicional da ciência.

Deste modo, nas práticas de ensino que se caracterizam por uma concepção tradicional da ciência são reproduzidos estereótipos de gênero e, portanto, as concepções dos/as professores/as e a forma como desenvolvem a sua prática pedagógica influencia as concepções de ciência e gênero dos/as estudantes (BATISTA et al., 2015; CAMACHOGONZÁLEZ, 2013; MANASSERO-MAS; VÁSQUEZ-ALONSO, 2003) e podem influenciar o interesse/desinteresse das alunas por carreiras científicas e tecnológicas, nomeadamente nas áreas de ciência, tecnologia, engenharia e matemática (CTEM) (BATISTA et al., 2015; 
2013). Assim, é necessário que a formação de professores/as contemple as questões de gênero na ciência para que possam lhes auxiliar na sua prática docente, pois um/a professor/a que não tem conhecimentos nessa área muito dificilmente será capaz de (os) implementá-los em sala de aula. Para uma educação de qualidade é necessário que os/as professores/as de ciências abordem, em sala de aula, questões de gênero e ciência, bem como também é necessário que desenvolvam um sentido crítico sobre as suas próprias estereotipias acerca do que é supostamente típico, e socialmente expectável, dos rapazes ou das raparigas e que promovam esta reflexão conjunta junto dos seus alunos e alunas de forma a proporcionar um ambiente de aprendizagem capaz de desmistificar e desconstruir estereótipos de gênero (BATISTA et al., 2013, 2015; BERGANO, 2015).

Mas, para que os/as futuros/as docentes considerem as questões de gênero e a ciência nas suas aulas é necessário não só que tenham conhecimento acerca delas, mas também que estejam dispostos a usá-las e, para isso, é fundamental que lhes reconheçam o mérito e a importância enquanto tema necessário capaz de promover a aprendizagem e o desenvolvimento cognitivo, afetivo ou social dos seus/suas alunos/as. Para Bernestein (1990) e MORAIS et al. (2000), o desempenho do sujeito em um dado contexto depende da posse de orientação específica de codificação para esse contexto, que significa que o sujeito deve ter regras de reconhecimento e de realização. As primeiras dizem respeito ao sujeito ser capaz de reconhecer a especificidade do contexto; as segundas referem-se à capacidade do sujeito de produzir um determinado desempenho, adequado a esse contexto. Porém, não basta ter regras de reconhecimento e de realização adequadas, é preciso também ter motivações, interesses e valores apropriados a esse contexto, ou seja, depende também da posse de disposições socioafetivas e percepções favoráveis a esse contexto.

Para Lahire (2004), uma disposição é o produto incorporado de uma socialização e, portanto, é uma realidade reconstruída pelo sujeito. Trata-se de princípios geradores de práticas que refletem crenças, formas de agir e pensar que se traduzem nas ações do sujeito. Lahire (2004) considera que as disposições determinam a forma como o sujeito age, pensa, fala, sente e percebe o mundo que o rodeia. 0 autor distingue três tipos de disposições: disposições para agir, disposições para crer e disposições para sentir. Considera também que é importante distinguir as disposições para agir das disposições para crer, às quais reserva o nome de crenças (normas, modelos, valores, ideais...) que estão ligadas a normas sociais produzidas, suportadas e difundidas por diversas instituições, como é o caso da família e da escola. Estas crenças, embora por vezes sejam fortemente incorporadas pelos indivíduos, não podem ser, logo à partida, sistematicamente assimiladas a disposições para agir (LAHIRE, 2005). Porém, as crenças, disposições para crer, podem atuar de forma a promover o desenvolvimento de disposições para agir.

\section{Finalidades e objetivos}

Esta investigação é parte integrante de uma pesquisa mais ampla relacionada com o conhecimento de futuros/as docentes acerca das questões de gênero na ciência e da sua percepção acerca da influência que a prática pedagógica tem no interesse e escolhas profissionais de alunos/as por carreiras científicas e tecnológicas. Assim, é intenção deste 
estudo dar a conhecer e caracterizar a percepção de futuros/as docentes portugueses face à sub-representação feminina nas áreas e carreiras científicas e tecnológicas.

Neste contexto, foram definidos dois objetivos de investigação: 1) Perceber se os/as futuros/as docentes consideram haver profissões típicas de determinado sexo, bem como profissões em que ainda prevalece a invisibilidade feminina; 2) Perceber se os/as futuros/ as docentes têm a percepção de haver diferenças de aptidões entre homens e mulheres, bem como se consideram que a prática pedagógica pode influenciar o interesse e as escolhas profissionais dos/as alunos/as por carreiras científicas e tecnológicas.

\section{Metodologia}

Para analisar as respostas dos/as futuros/as docentes, recorreu-se a uma metodologia de natureza essencialmente qualitativa baseada na análise de conteúdo que, segundo Bardin (2010) e Coutinho (2011), é considerada adequada quando se pretende categorizar as descrições de narrativas teóricas e fazer inferências acerca do texto descrito e posterior interpretação à luz do quadro teórico.

0 estudo de caso foi realizado com 28 futuros/as docentes portugueses ( 25 do sexo feminino e três do sexo masculino), estudantes do curso de mestrado em Educação PréEscolar e Ensino do $1^{\circ}$ Ciclo do Ensino Básico ( $1 .^{\circ}$ e $2 .^{\circ}$ anos), com idades compreendidas entre os 20 e os 30 anos. Para garantir o anonimato das/dos participantes do estudo, a cada futuro/a docente foi atribuído um código representado pelas letras $\mathrm{F}$ (feminino) ou M (masculino) para identificar o sexo e um número.

Para a recolha de dados, utilizou-se como instrumento um questionário que foi elaborado em função dos objetivos de investigação definidos. 0 questionário foi aplicado em um estudo piloto cuja amostra apresentava características semelhantes às deste estudo, o que permitiu a sua validação. Para garantir maior validade e fidelidade recorreu-se também a um painel de juízes.

0 questionário é composto majoritariamente por questões de resposta aberta e por algumas questões de resposta fechada nas quais era pedida uma justificação à resposta dada e, portanto, embora a investigação seja predominantemente qualitativa, também assume características quantitativas. Para este trabalho, que é parte integrante de uma pesquisa mais ampla, tal como já foi mencionado, selecionaram-se as questões relacionadas com os objetivos anteriormente referidos. 0 questionário foi entregue ao Instituto Superior de Educação onde os/as futuros/as docentes estudam e foi respondido individualmente em uma das aulas do curso de mestrado. Fez-se também um cruzamento de dados entre as respostas dadas às questões e o sexo dos/as futuros/as docentes, o que permitiu refinar a informação obtida.

Convém salientar que para cada objetivo da investigação foram definidas unidades de análise que, por sua vez, se dividem em categorias de análise que tiveram em consideração os pressupostos teóricos assumidos, bem como as respostas dadas pelos participantes e a relação entre elas.

Deste modo, uma primeira análise, mais global e genérica, teve início com uma leitura geral das respostas dadas pelos/as participantes aos questionários, que permitiu 
definir e identificar categorias de análise que evidenciam as respostas obtidas. Estas unidades de análise foram estudadas criteriosamente de modo a se verificar a sua coerência com o tema estudado e o referencial teórico da investigação. Constatou-se que alguns dos argumentos apresentados pelos/as participantes para justificar determinadas respostas nem sempre eram coerentes com a pergunta ou o tema da investigação.

Outros argumentos são fruto do senso comum formado a partir de hábitos, crenças e preconceitos que tendem a ser transmitidos de geração em geração. Desta forma, foi necessário distinguir as categorias de análise em argumentos socializados, argumentos inválidos e argumentos válidos, em função das respostas dadas. Consideraram-se categorias de análise com argumentos socializados aquelas que contemplam resposta cujos registros apresentam argumentos estereotipados acerca do tema estudado. Consideraram-se categorias de análise com argumentos inválidos aquelas que permitem agrupar as respostas que contenham registros que indicam que as/os participantes não compreenderam a pergunta, sendo a resposta incoerente em relação à mesma e, portanto, as suas explicações são divergentes em relação ao tema estudado que são as questões de gênero e a ciência, segundo o referencial teórico escolhido nesta pesquisa. Consideraram-se categorias de análise com argumentos válidos aquelas que permitem agrupar as respostas que apresentam registros cujas explicações e argumentos são coerentes com o tema da investigação.

\section{Apresentação e discussão dos resultados}

Nesta seção, apresentam-se os resultados em função dos dois objetivos de investigação definidos. Porém, antes de se apresentarem os resultados propriamente ditos, convém ressaltar que os/as participantes do estudo - futuros/as docentes estudantes do curso de mestrado em Educação Pré-Escolar e Ensino do $1^{\circ}$ Ciclo do Ensino Básico - são majoritariamente do sexo feminino (25 futuras professoras e três futuros professores), o que corrobora os estudos de Eurydice, da European Commission (2015) e de Bergano (2015) quando referem que a profissão docente é exercida principalmente por mulheres, especialmente nos primeiros níveis de ensino.

Percepção dos/as futuros/as docentes acerca da existência de profissões típicas de determinado gênero e profissões onde prevalece a invisibilidade feminina

Para caraterizar a percepção dos/as futuros/as docentes acerca da relação entre as diferentes profissões e o sexo foram construídas duas unidades de análise, U1 - profissão e sexo (tabela 1), e U2 - profissão e invisibilidade feminina (tabela 2). Cada uma destas unidades é composta por três categorias de análise, como a seguir se apresentam.

\section{Unidade U1 - profissão e sexo}

Relativamente à unidade U1 - profissão e sexo (tabela 1), procurou-se saber se os/ as futuros/as docentes consideram que a sua futura profissão, ou outra qualquer, é típica de determinado sexo. 
Tabela 1 - Unidade de análise U1 - profissão e sexo - e respectivas categorias.

\begin{tabular}{c:c} 
U1) Profissão e sexo & \\
\hline \multicolumn{1}{c}{ Categorias } & Evidências/registros \\
\hline $\begin{array}{l}\text { UC1.1 - Considera que a profissão docente, ou outra qualquer, é típica de um determinado } \\
\text { sexo mas não justifica ou justifica com argumentos inválidos ou socializados. }\end{array}$ & 10 (36\%) \\
\hline $\begin{array}{l}\text { UC1.2 - Considera que a profissão docente, ou outra qualquer, não é típica de um } \\
\text { determinado sexo, mas não justifica ou justifica com argumentos inválidos. }\end{array}$ & 11 (39\%) \\
\hline $\begin{array}{l}\text { UC1.3 - Considera que a profissão docente, ou outra qualquer, não é típica de um } \\
\text { determinado sexo e justifica com argumentos válidos. }\end{array}$ & 7 (25\%) \\
\hline
\end{tabular}

Fonte: elaboração das autoras.

Foram identificadas 10 evidências/registros na categoria UC1.1 (Considera que a profissão docente, ou outra qualquer, é típica de um determinado sexo, mas não justifica ou justifica com argumentos inválidos ou socializados) que correspondem a 36\% do total de registros identificados. Destes 10 registros, sete são do sexo feminino (F2, F5, F10, F16, F19, F21, F22) e três do sexo masculino (M15, M27, M28) e todos eles se referem apenas à profissão docente, como, por exemplo:

Porque na nossa sociedade, a maioria dos professores/educadores são mulheres. (F2);

Porque mais de 90\% das educadoras de infância são de sexo feminino. (M15);

Na minha profissão (educadora de infância e professora do $1^{\circ}$ CEB) claramente existem mais mulheres... Provavelmente por estar muito associado ao cuidar, à afetividade, à proximidade com as crianças. É uma profissão que exige grande sensibilidade, caraterística que normalmente está mais relacionada às mulheres. (F16).

Os/as participantes consideram que a profissão docente é característica do sexo feminino, mas não apresentam argumentos válidos que o justifiquem ou justificam com argumentos socializados e estereotipados impostos pela sociedade, como é o caso da participante F16.

Pretendia-se perceber se os/as futuros/as docentes consideram haver profissões que devem ser de mulheres ou de homens, porém as suas respostas não evidenciam as suas opiniões pessoais, pois apenas se limitam a constatar e a descrever a realidade que os rodeia e, portanto, as suas explicações divergem do foco da questão que pretendia perceber as percepções pessoais dos participantes relativamente ao gênero e às profissões.

0 mesmo acontece com a natureza das explicações e argumentos apresentados pelos/as futuros/as docentes cujos registros foram agrupados na categoria UC1.2. Nesta categoria, 11 participantes, todos do sexo feminino (F1;F4; F6; F7; F8; F9; F13; F17; F23; F24; F26), que correspondem a 39\% do total de registros, embora considerem que a 
profissão docente, ou outra qualquer, não é típica de um determinado sexo, não justificam as suas opiniões, como por exemplo: “[...] todas as profissões podem ser exercidas pelos dois sexos" (F13). Mais uma vez, se percebe que apenas se trata de uma constatação e descrição do real, e não uma opinião formada acerca do tema.

Na categoria UC1.3 (Considera que a profissão docente, ou outra qualquer, não é típica de um determinado sexo e justifica com argumentos válidos) apenas foram identificados 7 registros (25\% do total de registros), também eles do sexo feminino (F3, F11, F12, F14, F18, F20, F25), como por exemplo: “Qualquer profissão pode ser exercida por qualquer pessoa habilitada, independentemente do gênero" (F12); "Nenhuma profissão deve ser destinada a um determinado sexo, pois o termo de igualdade deve ser praticado globalmente" (F18). Estas respostas permitem perceber as opiniões dos/as participantes que defendem a igualdade de gêneros nas diferentes profissões, apresentando como argumentos a habilitação do indivíduo e a igualdade de gêneros no acesso às profissões.

\section{Unidade U2 - profissão e invisibilidade feminina}

No que concerne à unidade U2 - profissão e invisibilidade feminina - tal como se pode observar na tabela 2, as categorias UC2.1 (Considera que não existem profissões onde prevalece a invisibilidade feminina e não justifica ou justifica com argumentos inválidos) e UC2.2 (Considera que existem profissões onde prevalece a invisibilidade feminina identificando algumas, mas não justifica ou justifica com argumentos inválidos) contemplam oito registros (sete do sexo feminino e um do sexo masculino) que representam $28,5 \%$ do total de registros identificados.

Tabela 2 - Unidade de análise U2 - profissão e invisibilidade feminina - e respectivas categorias.

\begin{tabular}{|c|c|}
\hline \multicolumn{2}{|l|}{ U2) Profissão e invisibilidade feminina } \\
\hline Categorias & Evidências/registros \\
\hline \multirow{2}{*}{$\begin{array}{c}\text { UC2.1 - Considera que não existem profissões onde prevalece a invisibilidade feminina e não } \\
\text { justifica ou justifica com argumentos inválidos. }\end{array}$} & $8(28,5 \%)$ \\
\hline & F1; F4; F7; F11; F12; F13; F17; M27 \\
\hline \multirow{2}{*}{$\begin{array}{l}\text { UC2.2 - Considera que existem profissões onde prevalece a invisibilidade feminina identificando } \\
\text { algumas, mas não justifica ou justifica com argumentos inválidos ou socializados. }\end{array}$} & $8(28,5 \%)$ \\
\hline & F2; F5; F9; F10; F14; M15; F19; F22 \\
\hline \multirow[b]{2}{*}{$\begin{array}{l}\text { UC2.3 - Considera que existem profissões onde prevalece a invisibilidade feminina, identificando } \\
\text { algumas e justifica com argumentos válidos. }\end{array}$} & $12(43 \%)$ \\
\hline & $\begin{array}{l}\text { F3; F6; F8; F16; F18; F20; F21; F23; F24 } \\
\text { F25; F26; M28 }\end{array}$ \\
\hline
\end{tabular}

Fonte: elaboração das autoras.

Em ambas as categorias (UC2.1 e UC2.2), curiosamente representadas pelo mesmo número de registros, os/as participantes geralmente não justificam as suas respostas e, quando o fazem, apresentam argumentos divergentes e incoerentes com tema da investigação. Relativamente à categoria UC2.1, os/as participantes são da opinião que não 
existem profissões onde prevalece a invisibilidade feminina. Estes resultados mostram que estes participantes não percebem o sexismo que ainda existe nas profissões. A participante F1 foi a única que expressou a sua opinião, e embora apenas tenha constatado um facto que ainda se verifica na sociedade atual, não justificou com argumentos válidos, mas sim com argumentos que fazem parte do senso comum (conhecimento adquirido a partir de experiências, vivências e observações do mundo): "Cada vez mais é visível uma igualdade de sexo, contudo a nível salarial a mulher ainda perde” (F1). Além disso trata-se de uma resposta contraditória uma vez que os argumentos apresentados são incoerentes. A participante F1 considera que não há sexismo nas profissões; refere que hoje em dia é cada vez mais visível a presença feminina, no entanto, considera que há diferenças salariais entre os gêneros, o que contraria a não existência de sexismo entre as profissões.

No que respeita à categoria UC2.2, os/as participantes são de opinião contrária. Consideram que há invisibilidade feminina em determinadas profissões e identificam algumas áreas sub-representadas pelo sexo feminino, como por exemplo as áreas das engenharias (F2, F5, F19); da construção civil (F10, M15) e da política (F14). Porém, muitos dos argumentos apresentados pelos/as participantes são fruto do senso comum formado a partir de hábitos, crenças e preconceitos que tendem a ser transmitidos de geração em geração e, por isso, não foram considerados argumentos válidos para justifıcar esta realidade acerca da invisibilidade feminina em certas profıssões, que ainda se faz sentir nos dias de hoje. A opinião apresentada pela participante F2 é exemplo destes argumentos: "Nas áreas das engenharias principalmente, uma vez que é uma área em que se lida com vários conhecimentos e equipamentos científicos" (F2). A participante F2 apresenta argumentos inválidos e estereotipados, pois transparece a ideia de que apenas os homens têm capacidades, competências e conhecimentos para lidar com equipamentos científicos próprios da área das engenharias.

Quanto à categoria UC2.3 (Considera que existem profissões onde prevalece a invisibilidade feminina identificando algumas e justifica com argumentos válidos), foi identificado um número significativo de registros (12 do total dos/as 28 participantes que representa 43\%), 11 do sexo feminino (F3, F6, F8, F16, F18, F20, F21, F23, F24, F25, F26) e um do sexo masculino (M28). Desta categoria fazem parte evidências como: "Nas engenharias. É claro que já existem mulheres na engenharia, mas sei que algumas têm dificuldade, mesmo ao longo do curso. Sofrendo até de discriminação, em que os homens professores não consideram que as mulheres tenham capacidade para tirar um curso de engenharia” (F21); "Tecnologia. Existem muito poucas mulheres a investir nesta área. Existe ainda o estereótipo de que esta área é mais dedicada para os homens (F25); “Cargos de chefia, engenharia. Porque ainda na sociedade há pessoas que acham que há profissões de homens e profissões para mulheres, a mentalidade é antiga. Embora este paradigma esteja a mudar e ainda bem" (M28).

Perante esses resultados relacionados com o primeiro objetivo da investigação, percebe-se que a maioria dos/as futuros/as docentes (64\%, categorias de análise UC1.2 e UC1.3), todos do sexo feminino, não considera existir profissões masculinas e femininas, porém um número considerável de participantes (39\%) apresentam respostas que apenas se limitam a constatar e a descrever a realidade que os rodeia e, portanto, as suas explicações e argumentos não evidenciam as suas opiniões e percepções pessoais relativamente ao gênero 
e às profissões. Apenas 25\% (categoria UC1.3) justificam com argumentos pertinentes para o tema estudado, pois apresentam respostas que permitem perceber as opiniões dos/as participantes que defendem a igualdade de gêneros nas diferentes profissões, apresentando como argumentos a habilitação do indivíduo e a igualdade de gêneros no acesso às profissões.

De igual forma, apenas 43\% dos/as participantes (categoria UC2.3) reconhecem que em algumas profissões ainda prevalece a invisibilidade feminina, principalmente nas relacionadas com as áreas de engenharia e tecnologia, apresentando como argumentos a existência de estereótipos de gênero que condicionam o acesso das mulheres às áreas da ciência, da tecnologia, da engenharia e da matemática. Estes resultados evidenciam que muitos dos/as futuros/as docentes são futuros/as profissionais capazes de motivar o interesse das alunas por profissões consideradas tipicamente masculinas. Contudo, 36\% (categoria UC1.1) dos inquiridos considera que a profissão docente, ou outra qualquer, é típica de um determinado sexo e $28,5 \%$ (categoria UC2.1) são da opinião de que não existem profissões onde prevalece a invisibilidade feminina e, portanto, não percebem o sexismo que ainda existe nas profissões.

De acordo com estes resultados, percebe-se que, por um lado, muitos/as destes/ as futuros/as docentes, embora acreditem que as profissões não são determinadas pelo gênero, apresentam argumentos que revelam falta de informação e conhecimento relativamente às questões de gênero e à igualdade nas profissões. Por outro lado, alguns/ mas destes/as docentes manifestam concepções e crenças androcêntricas acerca de determinadas profissões. Sabendo que a sub-representação da mulher no mercado de trabalho, nomeadamente em áreas como as ciências, tecnologias ou engenharias, está relacionada com a ideia equivocada da sociedade em geral em considerar estas profissões como tipicamente masculinas, é necessário que os/as futuros/as docentes desenvolvam um sentido crítico sobre as suas próprias estereotipias de forma a poderem desmistificar e desconstruir entre os/as estudantes esta concepção errada acerca das profissões (BATISTA et al., 2013; BERGANO, 2015; CASTILLO; GRAZZI; TACSIR, 2014; SAAVEDRA et al., 2011, 2014; SAAVEDRA; TAVEIRA; SILVA, 2010).

\section{Percepção dos/as futuros/as docentes acerca da existência de diferenças de aptidões entre homens e mulheres e da influência da prática pedagógica no interesse e nas escolhas profissionais dos/as alunos/as por carreiras científicas e tecnológicas}

Para saber se os/as futuros/as docentes acreditam haver diferenças de aptidões entre homens e mulheres, bem como se consideram que a prática pedagógica pode influenciar o interesse e as escolhas profissionais dos/as alunos/as por carreiras científicas e tecnológicas foram construídas duas unidades de análise, U3 - aptidões de homens/mulheres e interesse e escolhas profissionais por carreiras científicas e tecnológicas (tabela 3) e U4 - influência da prática pedagógica no interesse e escolha profissional de futuros/as alunos/as por carreiras científicas e tecnológicas (tabela 4). Cada uma destas unidades é composta por três categorias de análise como a seguir se apresentam. 


\section{Unidade U3 - aptidões de homens/mulheres e interesse e escolhas profissionais por carreiras científicas e tecnológicas}

Relativamente à Unidade U3 - aptidões de homens/mulheres e interesse e escolhas profissionais por carreiras científicas e tecnológicas (tabela 3), dos 28 participantes, uma das futuras docentes (F26) não respondeu a esta questão (correspondendo a um total de $4 \%$ do total de inquiridos/as).

Tabela 3 - Unidade de análise U3 - aptidões de homens/mulheres e interesse e escolhas profissionais por carreiras científicas e tecnológicas - e respectivas categorias.

\begin{tabular}{cc} 
U3) Aptidões de homens/mulheres e interesse e escolhas profissionais por carreiras científicas e tecnológicas \\
\hline Categorias & Evidências/registros \\
\hline $\begin{array}{c}\text { UC3.1 - Considera que existem diferenças de aptidões/competências entre homens e mulheres } \\
\text { e que essas diferenças influenciam o interesse e escolhas profissionais por carreiras científicas e } \\
\text { tecnológicas, mas não justifica ou justifica com argumentos inválidos ou socializados. }\end{array}$ & 10 (36\%) \\
\hline $\begin{array}{c}\text { UC3.2 - Considera que não existem diferenças de aptidões/competências entre homens } \\
\text { e mulheres que influenciam o interesse e escolhas profissionais por carreiras científicas e } \\
\text { tecnológicas, mas não justifica. }\end{array}$ & M27 F10; F14; F18; F24; \\
\hline UC3.3 - Considera que não existem diferenças de aptidões/competências entre homens \\
e mulheres que influenciam o interesse e escolhas profissionais por carreiras científicas e \\
tecnológicas e justifica com argumentos válidos. & F2; F5; F6; F11; F16; F19; F20; F21; \\
\hline Não respondeu & F22; F25; M28 F13; M15; F17; F23 \\
\hline
\end{tabular}

Fonte: elaboração das autoras.

Um número significativo de registros, 10 dos 28 (36\%) considera que existem diferenças de aptidões/competências entre homens e mulheres e que essas diferenças influenciam o interesse e escolhas profissionais por carreiras científicas e tecnológicas, mas não justificam ou justificam com argumentos inválidos ou socializados (categoria UC3.1). Entre estes registros/evidências, nove são do sexo feminino (F3, F4, F7, F8, F9, F10, F14, F18, F24) e um do sexo masculino (M27). Cinco das participantes (F4, F7, F8, F9, F10) não responderam, e os/as restantes deram justificações não válidas (incoerentes com a pergunta) ou estereotipadas, como por exemplo: "Na sociedade os homens são vistos como mais competentes e aptos para certos empregos" (F14); "Considero que as mulheres possuem aptidões diferentes das dos homens e que normalmente optam por carreiras científicas e tecnológicas" (F24).

No que respeita à categoria UC3.2 (Considera que não existem diferenças de aptidões/ competências entre homens e mulheres que influenciam o interesse e escolhas profissionais por carreiras científicas e tecnológicas, mas não justifica) apenas seis respostas, cinco de participantes do sexo feminino e um participante do sexo masculino (F1, F12, F13, M15, F17, F23) se enquadraram nesta categoria, correspondendo a um total de 21\% dos/ as futuros/as docentes inquiridos. Nenhum/a destes/as participantes apresentou qualquer 
tipo de justificação, como é o caso, por exemplo, da participante F23 que apenas apresenta uma constatação relativa à existência de um reduzido número de mulheres na área das tecnologias, sem, no entanto, se referir às aptidões entre homens e mulheres: "Concordo que o número de mulheres na área das tecnologias é reduzido” (F23).

Um número considerável de participantes, 11 (10 do sexo feminino e um do sexo masculino) que representam 39\% do total de respostas, manifesta igual opinião. Entendem não haver diferenças de aptidões/competências entre homens e mulheres que influenciam o interesse e escolhas profissionais por carreiras científicas, porém justificam a sua opinião com argumentos válidos e pertinentes para o tema e, portanto, as suas respostas enquadram-se na categoria UC3.3. Algumas destas respostas reconhecem a não existência de diferenças de aptidões entre homens e mulheres e que o sexo não influencia as aptidões, como por exemplo: "As mulheres são capazes de fazer tudo como os homens e isso nota-se, atualmente, na presença de cada vez mais mulheres em todas as áreas” (F5); "Porque tanto o sexo feminino como o masculino têm competências e capacidades para seguir qualquer carreira, caso de dedique e esforce" (F6).

Outras respostas apontam também para o reconhecimento da existência de estereótipos na sociedade que conduzem ou condicionam as mulheres para determinadas escolhas profissionais, como por exemplo: "Atualmente não existem coisas de homens e mulheres, todos podemos fazer tudo. Mas perante a sociedade a distinção de gênero é uma realidade, talvez porque a mudança é muito dura" (F19); "Considera-se ainda que as mulheres agem mais com o coração, logo, devia dedicar-se a carreiras mais delicadas. São estereótipos que foram criados pelas pessoas e ainda hoje isso está muito veiculado" (F25).

Perante estes resultados, é possível perceber que, por um lado, cerca de 39\% dos/ as participantes acredita que existem diferenças de aptidões entre homens e mulheres que influenciam as escolhas profissionais por carreiras científicas e tecnológicas. As crenças estereotipadas destes futuros/as docentes, que persistem em serem transmitidas de geração em geração e que são incorporadas no indivíduo pelo processo de socialização, condicionam a sua forma de pensar e, consequentemente, a sua forma de agir em contexto de sala de aula enquanto docente e, portanto, não são favoráveis à desmistificação dos estereótipos de gênero que ainda existem associados às profissões.

Por outro lado, cerca de 60\% dos/as participantes não acreditam na diferença de aptidões entre homens e mulheres. Destes 60\%, 39\% dos futuros/as professores/as demonstram ter um senso crítico e uma concepção mais elaborada acerca da igualdade entre os gêneros, pois justificam as suas respostas apresentando como argumentos a competência e a capacidade do cidadão e da cidadã enquanto indivíduo, sem fazer distinção entre aquilo que o homem sabe e pode fazer, ou aquilo que a mulher sabe ou pode fazer. Além disso, demonstram ter crenças (normas, modelos, valores, ideais...) bem formadas e informadas para fazer frente à existência de estereótipos impostos pela sociedade no que concerne à igualdade de gêneros nas profissões e, portanto, dispõem de disposições favoráveis para crer que, em última análise, poderão ser disposições para agir em contexto de sala de aula. 


\section{Unidade U4 - Influência da prática pedagógica no interesse e escolhas profissionais de futuros/ as alunos/as por carreiras científicas e tecnológicas}

No que respeita à Unidade U4 - influência da prática pedagógica no interesse e escolha profissional de futuros/as alunos/as por carreiras científicas e tecnológicas (tabela 4), procurou-se perceber se os/as futuros/as docentes consideram que a prática pedagógica docente pode influenciar o percurso acadêmico e profissional dos/as alunos/as.

Tabela 4 - Unidade de análise U4 - influência da prática pedagógica no interesse e escolha profissional de futuros/os alunos/as por carreiras científicas e tecnológicas - e respectivas categorias.

\begin{tabular}{ccc}
\hline U4) Influência da prática pedagógica e o interesse e escolhas profissionais de futuros/as alunos/as por carreiras científicas e tecnológicas \\
\hline \multicolumn{1}{c}{ Categorias } & Evidências/registros \\
\hline $\begin{array}{c}\text { UC4.1- Considera que a prática pedagógica não influencia nem motiva o interesse e as escolhas } \\
\text { profissionais das alunas por carreiras científicas e tecnológicas, mas não justifica ou justifica com } \\
\text { argumentos inválidos. }\end{array}$ & 5 (18\%) \\
\hline $\begin{array}{c}\text { UC4.2 - Considera que a prática pedagógica pode influenciar/motivar o interesse e as escolhas } \\
\text { profissionais das alunas por carreiras científicas e tecnológicas, mas não justifica ou justifica } \\
\text { com argumentos inválidos. }\end{array}$ & F1; F2; F5; F6; F7; F9; F10; F11; F12; F8; F13; F25 \\
\hline $\begin{array}{c}\text { UC4.3 - Considera que a prática pedagógica pode influenciar/motivar o interesse e as escolhas } \\
\text { profissionais das alunas por carreiras científicas e tecnológicas, justificando com argumentos } \\
\text { válidos. }\end{array}$ & F22; F23; F24; F26; M27; M28 \\
\hline
\end{tabular}

Fonte: elaboração das autoras.

Com esta pergunta, pretendia-se que os/as futuros/as docentes manifestassem a sua opinião relativamente à importância da prática pedagógica para a desmistificação dos estereótipos de gênero que ainda se fazem sentir e que condicionam as escolhas profissionais das alunas por carreiras científicas e tecnológicas.

Em um total de 28 participantes, apenas cinco (correspondendo a 18\%), todas elas do sexo feminino (F3; F4; F8; F13; F25), consideram que a prática pedagógica não influencia nem motiva o interesse e as escolhas profissionais das alunas por carreiras científicas e tecnológicas, mas não justificam ou justificam com argumentos inválidos, e por isso, as suas respostas foram agrupadas na categoria UC4.1.

Um número bastante significativo de futuros/as docentes, 22 (78,5\%) em um total de 28, considera que a prática pedagógica pode influenciar/motivar o interesse e as escolhas profissionais dos/as alunos/as por carreiras científicas e tecnológicas. No entanto, muitos destes/as futuros/as docentes não justificaram a sua opinião (F1, F2, F7, F9, F10, F11, F12, M27) e outros entenderam esta questão como a "influência geral" da prática pedagógica e não como a sua "influência para as questões de gênero" tendo justificado as suas respostas com argumentos inválidos, ou seja, argumentos incoerentes e divergentes da pergunta e do tema estudado (F5, F6, F8, F13, F14, M15, F17, F18, F19, F20, F22, F23, F24, F26, M27, M28). Deste modo, as suas respostas agruparam-se na categoria UC4.2, pois embora estes docentes percebam a desigualdade de gênero, mesmo que de modo mais simplista, não demonstraram ter uma visão crítica e elaborada acerca do tema. 
Muitas das justificações apresentadas por esses/as futuros/as docentes limitaramse a anuir acerca da influência e motivação da prática pedagógica sem, no entanto, se referirem às questões de gênero e às dificuldades que muitas alunas poderão ter ao longo do seu percurso acadêmico. Outras destas justificações, embora apresentem argumentos que apontam para o papel do/a professor/a enquanto motivante e cativador capaz de despertar o gosto pela disciplina, ou enquanto modelo em contexto de sala de aula, o que não deixa de ser uma condição necessária para influenciar o interesse dos/as alunos/as por escolhas profissionais, não apresentam argumentos válidos e pertinentes para o tema em questão, relacionado essencialmente com as escolhas profissionais por carreiras cientificotecnológicas, área na qual a presença feminina ainda é sub-representada. São exemplos dessas respostas os que a seguir se apresentam: "Por vezes quando os professores são motivadores, interessantes e dinâmicos estes fazem com que os seus alunos se interessem por carreiras científicas. Para tal é necessário ser um professor cativante e especial para os alunos" (F20). "O professor pode ser uma grande influência, uma vez que é tomado como modelo por alguns alunos, é natural que influencie nessas escolhas” (F16).

As respostas dadas por estes/as participantes, cujas justificações e argumentos divergem do tema estudado - influência da prática pedagógica para as questões de gênero - não revelam as suas verdadeiras disposições, motivações e ideais relativamente ao tema estudado. Embora percebam a desigualdade de gêneros, entende-se que a avaliação que fazem acerca da importância da prática pedagógica para as questões de gênero não é clara e precisa, o que deixa transparecer uma dúbia atuação futura e intencionalidade para promover ações de ruptura em contexto de sala de aula.

Apenas uma participante (3,5\%) justificou com argumentos válidos e pertinentes que a prática pedagógica pode influenciar/motivar o interesse e as escolhas profissionais dos/as alunos/as por carreiras científicas e tecnológicas tendo sida a sua resposta inserida na categoria UC4.4: "0 professor pode e deve motivar os alunos nas suas escolhas profissionais. Principalmente nas áreas referidas, sendo estas tão relacionadas à figura masculina. Mas tanto deve ser influenciada para essas áreas como para outras, mantendo clara a ideia de que não há profissões só para homens ou só para mulheres” (F21). A participante F21 justificou a sua resposta com argumentos relacionados com a prática pedagógica, as questões de gênero e as carreiras científicas e tecnológicas, demostrando ter conhecimento acerca do tema.

Esses resultados, relacionados com o segundo objetivo da investigação, deram a conhecer a percepção dos/as futuros/as docentes acerca das diferenças de aptidões entre homens e mulheres, bem como acerca da influência que a prática pedagógica pode ter no interesse e nas escolhas profissionais dos/as alunos/as por carreiras científicas e tecnológicas. Os dados revelam que grande parte destes/as futuros/as docentes considera haver diferenças de aptidões entre homens e mulheres que influenciam as suas escolhas profissionais por áreas e carreiras científicas e tecnológicas. Relativamente à prática pedagógica, muitos/as dos/as participantes afırmam que esta não tem qualquer influência nas escolhas profissionais dos/as alunos/as por carreiras científicas e tecnológicas, o que demonstra uma noção errada (equivocada) e que precisa ser desconstruída.

Embora muitos dos/as futuros/as docentes reconheçam a influência da prática pedagógica, encaram esta influência de forma generalizada sem se referirem à sua 
importância para a desmistificação dos estereótipos de gênero associados às escolhas profissionais. Apenas uma participante justifica a importância da prática pedagógica para a motivação, o interesse e as escolhas profissionais das alunas por carreiras científicas e tecnológicas com argumentos válidos e pertinentes, relacionados com as questões de gênero. As concepções e crenças manifestadas por esta participante acerca da influência da prática pedagógica para as questões gênero revelam uma socialização favorável para o tema, na medida em que defende claramente a ideia de que não há profissões só para homens ou só para mulheres.

De acordo com Lahire $(2004,2005)$, estas crenças podem ser ativadas ou desativadas dependendo do contexto. Depreende-se assim que os ideais defendidos por esta participante, que demostra ter conhecimento acerca do tema, são disposições favoráveis para crer (motivações, valores, concepções e percepções) que, em última análise, em contexto de sala de aula, poderão vir a ser disposições favoráveis para agir e promover a ruptura e a mudança destes conceitos com os seus alunos.

Perante estes resultados, percebe-se que a maioria destes/as futuros/as profissionais, mais uma vez, demostrou ter falta de conhecimento e sensibilidade para debater e abordar esses temas com os/as seus/suas alunos/as em contexto de sala de aula, comprometendo a sua futura prática pedagógica, enquanto intervenientes no processo de socialização e na formação de futuros/as cidadãos e cidadãs conscientes da igualdade entre os sexos.

\section{Conclusões e contribuições}

A sub-representação feminina nas áreas da ciência, tecnologia, engenharia e matemática (CTEM), tanto no nível acadêmico, como da sua representação no mercado de trabalho e em carreiras profissionais científicas e tecnológicas, foi ponto de partida para esta investigação. Tal como referem vários estudos (EURYDICE, 2011; EUROPEAN COMMISSION, 2015; BERGANO, 2015), ainda prevalece a ideia de que as profissões relacionadas com as áreas da saúde e da educação são mais adequadas para as mulheres, sendo que a profissão docente é exercida principalmente por mulheres, especialmente nos primeiros níveis de ensino. Essa ideia é sustentada pela própria amostra desta investigação cujos/as participantes (futuros/as docentes estudantes do curso de mestrado em Educação Pré-Escolar e Ensino do $1^{\circ}$ Ciclo do Ensino Básico) são maioritariamente do sexo feminino. Porém, para ultrapassar esta situação é necessário que a sociedade em geral, e os/as professores/as em particular, se desprendam de estereótipos de gênero e de ideias pré-concebidas associadas a esta temática, que tendem em persistir ao longo do tempo.

Neste sentido, esta investigação procurou perceber se estes/as futuros/as docentes consideram a existência de profissões típicas de determinado gênero ou profissões em que prevalece a invisibilidade feminina. Foi também propósito deste trabalho compreender se este grupo de futuros/as profissionais têm a percepção de haver diferenças de aptidões entre homens e mulheres, bem como se consideram que a prática pedagógica pode influenciar o interesse e as escolhas profissionais dos/as alunos/as por carreiras científicas e tecnológicas. Os resultados mostram que a maioria dos/as participantes demostra ter 
falta de conhecimento para abordar temas relacionados com a igualdade de gêneros nas áreas CTEM. Esta grave lacuna em questões relacionadas com a igualdade de gênero, mais tarde, irá ser passada, de forma mais ou menos consciente, para os/as alunos/as perpetuando desigualdades no tempo e no espaço.

A preocupante falta de argumentos válidos e coerentes com o tema estudado, revelada por alguns/mas futuros/as docentes, para debater estas questões em contexto de sala de aula, é justificada pelo seu conhecimento enviesado, fruto das suas próprias socializações e vivências pessoais. A presença de estereótipos associados ao gênero é ainda parte integrante da forma de pensar e, consequentemente, de agir, mesmo em jovens adultos, como é o caso dos/as participantes deste estudo, que não vivenciaram épocas em que prevalecia a opressão e a falta de liberdade de expressão.

Por uma lado, os resultados desta investigação dão a conhecer que grande parte dos/as futuros/as docentes que participaram nesta investigação expressam estereótipos de gênero. Deste modo, tal como defendem Bergano (2015) e Morales; Avilla e Espinosa (2016), as práticas pedagógicas, e em particular as futuras práticas pedagógicas, destes/ as docentes cuja visão relativamente ao gênero e à ciência ainda é androcêntrica, podem influenciar as escolhas de muitas alunas por carreiras científicas e tecnológicas, uma vez que as suas experiências escolares estão fortemente associadas a estereótipos de gênero e socioculturais vivenciados em contexto de sala de aula. As crenças estereotipadas destes futuros/as docentes condicionam a sua forma de pensar e, consequentemente, a sua forma de agir em contexto de sala de aula enquanto docentes e, portanto, não são favoráveis à desmistificação de estereótipos de gênero junto dos seus alunos e alunas.

Por outro lado, alguns/mas participantes demostraram ter algumas disposições favoráveis relacionadas com o tema. Para Bernstein (1990) e Lahire (2005), o desempenho do sujeito em um dado contexto depende, entre outros aspectos, da posse de disposições favoráveis a esse contexto, ou seja, depende de ter crenças, percepções, concepções, motivações e valores apropriados a esse contexto. Assim, esta investigação centrou-se nas crenças, percepções e formas de pensar que os/as futuros/as docentes têm relativamente às questões de gênero e à representação feminina nas áreas e carreiras científico-tecnológicas.

Tal como defende Lahire (2005), também neste estudo se considerou que estas crenças, incorporadas pelos sujeitos de forma mais ou menos forte, não podem ser, logo à partida, sistematicamente assimiladas a disposições para agir. Porém, acredita-se que as crenças, disposições para crer, podem atuar de forma a promover o desenvolvimento de disposições para agir, pois como defende o autor, estas crenças são contextuais e, como tal, podem ser alteradas em função do contexto de formação em os/as futuros/as docentes se inserem. Assim, depreende-se que docentes que percebem a desigualdade de gênero nas vocações profissionais apresentam disposições favoráveis e intencionalidade de promover ações de ruptura na sua prática pedagógica e, portanto, o mérito que reconhecem nesta ruptura promoverá nas suas futuras alunas (e alunos) interesses e motivações para as áreas da ciência, tecnologia, engenharia e matemática. Mas para que isso aconteça é necessário apostar em uma melhor formação de docentes.

Neste sentido, os resultados apresentados confirmam assimetrias de gênero que se institucionalizam nas carreiras científicas e tecnológicas em Portugal e revelam lacunas que precisam ser refletidas em novas propostas de formação de futuros docentes portugueses. 
Deste modo, esta investigação contribui para que se repense acerca da formação dos/as futuros/as docentes, pois um/a professor/a que não tem instrução e conhecimentos relacionados com estas questões muito dificilmente será capaz de transmiti-los e implementá-los em sala de aula. É necessário que a sua formação abarque a compreensão dos papéis de gênero nas áreas da ciência, tecnologia, engenharia e matemática (CTEM) e a consequente segregação da mulher no mercado de trabalho nestas áreas, para que lhes permita desenvolver um sentido crítico sobre as suas próprias estereotipias e poderem, também eles, desmistificar e desconstruir estereótipos de gênero (BERGANO, 2015; CASTILLO; GRAZZI; TACSIR, 2014; MORALES; AVILLA; ESPINOSA, 2016; SAAVEDRA et al., 2011, 2014; SCHIEBINGER, 2010) e dar o seu contributo para uma futura sociedade mais justa, equilibrada e livre para todos/as.

Para além disso, a falta de formação e informação relacionada com estas questões, que são identificadas nos/as alunos/as em formação, poderá ajudar os/as seus/suas formadores/as a perceber a necessidade de debater e esclarecer esses aspectos durante a formação, ajudando os/as futuros/as docentes a ultrapassarem essas potenciais barreiras/ dificuldades face às questões de gênero em contexto de sala de aula.

\section{Referências}

ARCHER, Louise; DEWITT, Jennifer; WONG, Billy. Spheres of influence: what shapes young people's aspirations at age 12/13 and what are the implications for education policy? Journal of Education Policy, London, v. 29, n. 1, p. 58-85, 2014.

BARDIN, Laurence. Análise de conteúdo. 5. ed. Lisboa: Edições 70, 2010.

BATISTA, Irinéa L. et al. Formação de professores no Brasil e questões de gênero feminino em atividades científicas. In: X ENCONTRO NACIONAL DE PESQUISA EM EDUCAÇÃO EM CIÊNCIAS (ENPEC), 10., 2015, Águas de Lindóia. Anais... Águas de Lindóia: Enpec, 2015. p. 1-9. Disponível em: <http://www.abrapecnet. org.br/enpec/x-enpec/anais2015/trabalhos.htm>. Acesso em: 25 jan. 2017.

BATISTA, Irinéa L. et al. Saberes docentes e invisibilidade feminina nas ciências. In: ENCONTRO NACIONAL DE PESQUISA EM EDUCAÇÃO EM CIÊNCIAS (ENPEC), 9., 2013, Águas de Lindoia. Anais... Águas de Lindóia: Enpec, 2013. p. 1-8. Disponível em: <http://abrapecnet.org.br/atas_enpec/ixenpec/atas/>. Acesso em: 25 jan. 2017.

BERGANO, Sofia. A promoção da igualdade de gênero no trabalho como tarefa educativa. Revista de Estudios e Investigación en Psicología y Educación, Coruña, v. extra, n. 7, p. 46-49, 2015.

BERNSTEIN, Basil. The structuring of pedagogic discourse: class, codes \& control. v. 4. London: Routledge, 1990.

CAMACHO-GONZÁLEZ, Johanna. Concepciones sobre ciencia y género en el profesorado de química: aproximaciones desde un estudio colectivo de casos. Ciência \& Educação, Bauru, v. 19, n. 2, p. 323338, 2013. 
CASTILLO, Rafael; GRAZZI, Matteo; TACSIR, Ezequiel. Women in science and technology: what does the literature say? Washington, DC: Inter-American Development Bank, 2014. Disponível em: <https:// publications.iadb.org/bitstream/handle/11319/6047/CTI\%20TN\%20Women\%20in\%20Science\%20 and\%20Technology.pdf?sequence=1>. Acesso em: 25 jan. 2017.

COMISSÃO PARA CIDADANIA E IGUALDADE DE GÊNERO. A igualdade de gênero em Portugal. Lisboa: Comissão para a Cidadania e Igualdade de Gênero, 2015.

COUTINHO, Clara P. Metodologia da investigação em ciências sociais e humanas: teoria e prática. 2. ed. Coimbra: Almedina, 2011.

DAVID, Rute; PAIXÃO, Maria P.; SILVA, José T. Interesses e competências percebidas na infância: um estudo com crianças do ensino básico. Revista Brasileira de Orientação Profissional, São Paulo, v. 16, n. 1, p. 49-58, 2015.

DEWITT, Jennifer et al. Young children's aspirations in science: the unequivocal, the uncertain and the unthinkable. International Journal of Science Education, London, v. 35, n. 6, p. 1037-1063, 2013.

EUROPEAN COMMISSION. She figures 2015: gender in research and innovation. statistics and indicators. Brussels: European Commission, 2015.

EURYDICE. Diferenças de gênero nos resultados escolares: estudo sobre as medidas tomadas e a situação atual na Europa. Bruxelles: Eurydice, 2011.

FIÚZA, Ana L.; PINTO, Neide Maria; COSTA, Elenice Rosa. Desigualdades de gênero na universidade pública: a prática dos docentes das ciências agrárias em estudo. Educação e Pesquisa, São Paulo, v. 42, n. 3, p. 803-818, 2016.

FLOURI, Eirini et al. Neighbourhood, school and family determinants of children's aspirations in primary school. Journal of Vocational Behavior, Milwaukee. 87, p. 71-79, 2015.

FOUAD, Nadya et al. Women's reasons for leaving the engineering field. Frontiers in Psychology, Lausanne, v. 8, article 875, p. 1-11, 2017.

LAHIRE, Bernard. Patrimónios individuais de disposições: para uma sociologia à escala individual. Sociologia, Problemas e Práticas, Lisboa, n. 49, p. 11-42, 2005.

LAHIRE, Bernard. Retratos sociológicos: disposições e variações individuais. Porto Alegre: Artmed, 2004.

LARANJEIRA, Márcia. A formação do autoconceito vocacional em contexto académico e social. 2015. $114 f$. Dissertação (Mestrado) - Faculdade de Psicologia da Universidade de Lisboa, Lisboa, 2015.

LARANJEIRA, Márcia; TEIXEIRA, Maria Odília. Perceção do feedback do professor e autoconceito vocacional. Revista Brasileira de Orientação Profissional, Florianópolis, v. 17, n. 2, p. 211-223, 2016.

LESLIE, Sara J. et al. Expectations of brilliance underlie gender distributions across academic disciplines. Science, New York, v. 347, n. 6219, p. 262-265, 2015. 
MARTINS, Patrícia. Mulheres nas ciências e tecnologias: escolhas e constrangimentos. 2011. $46 f$. Dissertação (Mestrado) - Universidade do Minho, Braga, 2011.

MORAIS, Ana Maria et al. Estudos para uma sociologia da aprendizagem. Lisboa: Instituto de Inovação Educacional e Centro de Investigação em Educação da Faculdade de Ciências da Universidade de Lisboa, 2000.

MORALES, Marie Paz E.; AVILLA, Ruel A.; ESPINOSA, Allen A. Does gender inequality influence interest in pursuing a career in science or mathematics teaching? Issues in Educational Research, Sydney, v. 26, n. 1, p. 65-81, 2016.

SAAVEDRA, Luísa; TAVEIRA, Maria C.; SILVA, Ana Daniela. A subrepresentatividade das mulheres em áreas tipicamente masculinas: factores explicativos e pistas para a Intervenção. Revista Brasileira de Orientação Profissional, Florianópolis, v. 11, n. 2, p. 49-59, 2010.

SAAVEDRA, Luísa et al. (A)simetrias de gênero no acesso às engenharias e ciências no ensino superior público.Ex Aequo, Lisboa, v. 23, p. 163-177, 2011.

SAAVEDRA, Luísa et al. Dilemmas of girls and women in engineering: a study in Portugal. Educational Review, London, v. 66, n. 3, p. 330-344, 2014.

SCHIEBINGER, Londa. Gender, science and technology: a report of the expert group meeting, United Nations Division for the Advancement of Women in cooperation with Unesco. Paris: Unesco, 2010. Disponível em: <http://www.un.org/womenwatch/daw/egm/gst_2010/Schiebinger-BP.1-EGM-ST.pdf>. Acesso em: 24 fev. 2017.

TRACEY, Terence J. G.; CAULUM, David. Minimizing gender differences in children's interests assessment: development of the inventory of children's activities-3 (ICA-3). Journal of Vocational Behavior, Milwaukee, v. 87, p. 154-160, 2015.

VERVECKEN, Dries; HANNOVER, Bettina; WOLTER, Ilka. Changing (s)expectations: how gender fair job descriptions impact children's perceptions and interest regarding traditionally male occupations. Journal of Vocational Behavior, Milwaukee, v. 82, n. 3, p. 208-220, 2013.

Recebido em: 10.08.2017

Revisões em: 25.10.2017

Aprovado em: 06.12.2017

Isabel Marília Borges Fernandes é doutora em didática das ciências sociais, experimentais e matemáticas, pela Universidade de Valladolid - Faculdad de Educación y Trabajo Social Universidad de Valladolid, Espanha.

Sofia Cardim é doutora em economia aplicada, pela Universidade de Santiago de Compostela - Faculdad de Ciencias Económicas y Empresariales - Universidad de Santiago de Compostela, Espanha; Formadora para a Igualdade de Gênero. 